\title{
Revisitando o conceito de interação
}

\author{
Isabel Muniz-Lima * \\ Valdinar Custódio Filho **
}

\begin{abstract}
Resumo: Este artigo retoma uma discussão relacionada a um fenômeno que costuma ser considerado na linguística textual como já estabilizado: a interação. Nesse sentido, salienta-se como Kerbrat-Orecchioni (1990, 1992, 2005) e Marcuschi (2010) evidenciaram uma diversidade de práticas comunicativas que são intrinsecamente relacionadas à configuração das interações. Assim, busca-se ampliar essa discussão para que sejam contemplados outros modos de interagir, como aqueles que se verificam em torno de gêneros e hipergêneros das mídias digitais. Essa proposta complexifica a discussão em torno do termo "interação" e fornece contribuições teóricas importantes para os estudos que se voltam às estratégias de construção dos sentidos.

Palavras-chave: Interação. Modos de interagir. Mídias digitais.
\end{abstract}

Abstract: This article takes back a discussion related to a phenomenon that is largely considered in text linguistics as already established: the interaction. In this article, we emphasize how Kerbrat-Orecchioni (1990, 1992, 2005) and Marcuschi (2010) put in evidence various communicative practices that are intrinsically related to the configuration of interaction. Thus, we aim to widen this discussion so other modes of interaction could be considered, such as those concerned with genres and hypergenres of digital media. This proposal gives complexity to a discussion about the term "interaction" and offers important theoretical contributions to studies that analyze strategies of meaning construction.

Keywords: Interaction. Modes of interaction. Digital media.

Résumé: Cet article reprend une discussion liée à un phénomène qui est généralement considéré en linguistique textuelle comme déjà stabilisé: l'interaction. Il est souligné comment Kerbrat-Orecchioni (1990, 1992, 2005) et Marcuschi (2010) ont mis en évidence une diversité de pratiques communicatives intrinsèquement liées à la configuration des interactions. Nous cherchons à élargir cette discussion afin que d'autres façons d'interagir soient envisagées, telles que celles qui se produisent autour des genres et des hypergenres des médias numériques. Cette proposition complexifie la discussion du terme "interaction" et fournit d'importantes contributions théoriques aux études qui mettent l'accent sur les stratégies de construction des significations.

Mots-clés: Interaction. Modes d’interagir. Médias numériques.

\footnotetext{
* Doutoranda no Programa de Pós-Graduação em Linguística da Universidade Federal do Ceará (PPGLin/UFC) e membro do grupo de pesquisa Protexto (UFC). http://orcid.org/o0oo-0003-2809-8292 ${ }^{* *}$ Professor adjunto do Curso de Letras e do Mestrado Profissional em Letras (Profletras) da Universidade Estadual do Ceará (UECE) e membro do grupo de pesquisa Protexto (UFC). http://orcid.org/oooo-0001$7704-8836$
}

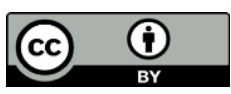

Este artigo está licenciado sob forma de uma licença Creative Commons Atribuição 4.0 Internacional, que permite uso irrestrito, distribuição e reprodução em qualquer meio, desde que a publicação original seja corretamente citada. https://creativecommons.org/licenses/by/4.0/deed.pt_BR. 


\section{Introdução}

A linguística textual (doravante LT) da atualidade se assenta numa concepção de texto como evento (BEAUGRANDE, 1997, seguido por muitos outros), a qual implica, obrigatoriamente, assumir que os processos de construção dos sentidos com vistas à manifestação da coerência só ocorrem com o acontecimento de textos em situações reais de interação. Disso se depreende que essa coerência depende de um conjunto de fatores (materialidade das linguagens, ação e papel social dos sujeitos, aparato sociocognitivodiscursivo, etc.), os quais se efetivam na interação. A assunção (deveras incontestável, em nossa área) de tal premissa leva os estudiosos de LT a usarem, com muita frequência, o termo “interação" como se este remetesse a um fenômeno já devidamente bem conceituado.

Talvez, para muitas pesquisas, a problematização desse conceito possa não ser necessária; o que se quer investigar e se quer dizer pode ser estabelecido com uma noção generalizada de interação, a qual se coaduna aos postulados assumidos. Contudo, para muitas outras pesquisas, uma discussão mais refinada sobre o fenômeno, a qual desemboca na consideração de que há distintos modos de interação, pode ser necessária, na medida em que o ato científico de destrinchar a complexidade desses modos de interação pode ajudar a questionar/sugerir novos modos de caracterizar os demais fenômenos responsáveis pela coerência textual.

Tendo, então, como mote a constatação de que há, sim, muito e mais a ser dito sobre o fenômeno da interação, intentamos propor uma discussão inicial neste artigo. Para tanto, partimos de duas propostas teóricas que estabelecem - explícita ou implicitamente - alguns parâmetros caracterizadores dessa dimensão dos processos comunicativos. Kerbrat-Orecchioni (1990, 1992, 2005) e Marcuschi (2010) investigaram uma diversidade de práticas comunicativas sob a perspectiva da oralidade e da escrita e, com isso, deixaram latente a necessidade de refletir sobre a complexidade do conceito 
de interação e de seus modos. Neste artigo, retomamos a discussão em torno desse conceito e propomos que a noção de interação seja considerada a partir de um conjunto amplo de aspectos - alguns considerados por Kerbrat-Orecchioni, outros por Marcuschi, e outros sugeridos por nós.

Inicialmente, apresentamos uma discussão acerca das contribuições de KerbratOrecchioni (1990, 1992, 2005) e de Marcuschi (2010) para os estudos da interação e levantamos algumas problemáticas em torno do tratamento dado ao fenômeno pelos autores. Essa discussão é fundamental para que se entenda a proposta que fazemos, na sequência, de uma revisão do tratamento dado ao conceito de interação. Nessa ampliação, consideramos que as múltiplas práticas comunicativas realizadas hoje por meio de gêneros e hipergêneros disponibilizados nas mais variadas mídias também contribuem para evidenciar a importância de uma reflexão mais aprofundada sobre a noção de interação. Desse modo, buscamos contemplar modos de interação que não estavam no foco de Kerbrat-Orecchioni e de Marcuschi, como aqueles possibilitados por uma configuração que envolve, além dos sistemas semióticos oral e escrito, do grau de formalidade e dos papéis sociais, aspectos como a sincronicidade, a gestão das vozes e o tipo de mídia.

\section{A noção de interação sob a perspectiva de Kerbrat-Orecchioni}

Nos dois primeiros tomos de Les interactions verbales (1990 e 1992) e em Le discours en interaction (2005), Kerbrat-Orecchioni se debruça sobre o conceito de interação e sobre a configuração de modos de comunicação na perspectiva da conversação. Nesses estudos, o foco da autora é sempre voltado para a análise de aspectos que caracterizam as trocas face a face entre interlocutores. Sobre sua abordagem do termo "interação", lemos, logo no início do tomo I de Les interactions verbales (1990), o seguinte: 
tudo ao longo do desenrolar de uma troca comunicativa qualquer, os diferentes participantes, os quais chamaremos de "interactantes", exercem, uns sobre os outros, uma rede de influências mútuas - falar é trocar, e é trocar trocando (KERBRAT-ORECCHIONI, 1990, p. 17; grifos da autora) ${ }^{1}$.

A interação é compreendida, portanto, em seu sentido mais geral, ou seja, como uma prática comunicativa que envolve uma rede de influências estabelecidas entre os interlocutores. Em Le discours en interaction (2005), Kerbrat-Orecchioni reforça essa perspectiva mais ampla do fenômeno e menciona que a interação se refere a uma "ação de dois (ou mais) objetos ou fenômenos um sobre o outro" (p. 14)². Para ela, o conceito de interação encontra-se relacionado a uma "ação conjunta" (p. 15) 3 empreendida pelos participantes de uma prática.

A autora faz ainda uma referência à definição de Goffman, por meio da qual o termo é visto, de modo semelhante, como uma influência recíproca que os participantes exercem uns sobre os outros quando estão em presença física imediata. Para Goffman (apud Kerbrat-Orecchioni, 2005), a noção de interação se aproxima do termo "encontro", o que deixa clara a escolha do autor, e também de Kerbrat-Orecchioni (2005), em investigar a interação no âmbito das práticas comunicativas estabelecidas face a face.

No capítulo inicial do segundo tomo de Les interactions verbales, a autora apresenta a definição de Labov e Fanshel para o termo "interação": "uma ação que afeta (altera ou mantém) as relações, próprias e dos outros, na comunicação face a face” (1992, p. 9) ${ }^{4}$. Vê-se que, nessas conceituações, a pesquisadora procura relacionar a noção de

\footnotetext{
${ }^{1}$ Tradução livre para "tout au long du déroulement d'un échange communicative quelconque, les différents participants, que l'on dira done des 'interactans', exercent les uns sur les autres un reseau d'influences mutuelles - parler, c'est échanger, et c'est changer en échangeant". Optamos, neste artigo, por apresentar as citações de obras estrangeiras traduzidas no corpo do texto, reproduzindo o trecho original em notas de rodapé. Registramos que todas as traduções apresentadas são de nossa responsabilidade.

2 "l'action de deux (ou plusieurs) objets ou phénomènes l'un sur l'autre" (KERBRAT-ORECCHIONI, 2005, p. 14).

3 "un système d'influences mutuelles, ou bien encore à une action conjointe" (KERBRAT-ORECCHIONI, 2005, p. 15).

4 "une action qui affecte (altère ou maintient) les relations de soi et d'autrui dans la communication de face-à-face" (KERBRAT-ORECCHIONI, 1992, p. 9).
} 
interação às relações comunicativas que se estabelecem entre os interlocutores em situações face a face.

Embora mantenha firme seu foco nas situações de interação face a face, a autora enfatiza que o termo não deve ser tomado somente em relação à ideia de "oralizar sempre para alguém" sob o risco de se reduzir o poder teórico e descritivo do termo e mascarar características específicas de cada interação (KERBRAT-ORECCHIONI, 2005, p. 16). Mesmo não utilizando a expressão "modos de interação", a autora já anunciava a existência de um conjunto diversificado de aspectos configuradores de práticas comunicativas distintas.

Na conclusão do primeiro tomo de Les interactions verbales, a autora apresenta a definição de interação proposta pelo pesquisador K. R. Scherer, em que essa noção está ligada a um "processo pelo qual dois ou mais atores co-orientados, seguindo sequências de comportamentos orientados para um objetivo, transmitem-se informações de uma maneira mutuamente contingente" (KERBRAT-ORECCHIONI, 1990, p. 150)5 . Para o autor, esse processo estaria, necessariamente, vinculado a "configurações de sinais multicanais”, ou seja, a "inflexões, olhares, gestos, mímicas” (KERBRAT-ORECCHIONI, 1990, p. 150) ${ }^{6}$. Mais uma vez, a autora reforça seu posicionamento em relação ao termo “interação" e acrescenta alguns fatores que configuram modos de interação específicos de práticas comunicativas face a face. Nessa perspectiva, a noção de interação está diretamente imbricada às situações em que os interlocutores encontram-se em condições de "engajarem-se" ou de apresentarem uma atitude responsiva imediata7.

Em conformidade com o pensamento bakhtiniano, a autora ratifica o princípio de que toda interação é dialógica, pois é sempre tomada por um locutor que convoca outros discursos, ou outras vozes. Contudo, segundo Kerbrat-Orecchioni (2005), embora toda interação seja dialógica, nem toda interação é dialogal. Nesse sentido, a

\footnotetext{
5 "un processus par lequel deux ou plusieurs acteurs co-orientés, suivant des séquences de comportement orientées vers un but, se transmettent l'information d'une manière mutuellement contingente, grâce à des configurations de signes multicanales" (KERBRAT-ORECCHIONI, 1990, p. 150).

6 "d'inflexions, de regards, de gestes, de mimique" (KERBRAT-ORECCHIONI, 1990, p. 150).

${ }^{7}$ Para nós, a conceituação de interação proposta por Kerbrat-Orecchioni e os autores que ela segue contempla as situações de comunicação síncronas mediadas pela oralidade. Trataremos do critério de (as)sincronicidade posteriormente.
} 
autora distingue interação monologal de interação dialogal: na primeira, o interlocutor é, no dizer da autora, "fictício", e a resposta dada ao locutor, portanto, é apenas pressuposta. Na interação dialogal, por sua vez, há um interlocutor concreto, que pode, efetivamente, tomar o turno de fala.

Ao tratar essa questão, a pesquisadora menciona um tipo de interação em que há sequência monologal "monogerida”. Embora não esteja preocupada em enfatizar o conceito do termo "monogerido", Kerbrat-Orecchioni (2005) parece se referir aos casos em que o locutor tem controle do que está sendo dito. Esse aspecto, a nosso ver, merece uma reflexão mais aprofundada, a fim de que possamos perceber as nuances de uma interação dita mais monogerida e de outras que, por sua vez, parecem se configurar de modo mais poligerido. Essa questão será retomada posteriormente.

Na perspectiva de Kerbrat-Orecchioni (2005), portanto, para que exista interação, é preciso que haja um feedback, ou uma resposta imediata por parte do interlocutor, o que exclui, portanto, as situações em que os interlocutores não estão em presença, ou seja, em que os interlocutores não se encontram face a face e também aquelas situações em que o tempo de resposta do interlocutor pode ser prolongado:

\begin{abstract}
De fato, a noção de interação implica que o destinatário esteja em condição de influenciar ou interferir no comportamento do locutor de maneira imprevisível, mesmo quando ele está engajado na construção do seu discurso; em outras palavras, para que haja interação, é preciso que se observem certos fenômenos de retorno imediato (ou de "reflexividade", para retomar um termo que a literatura interacionista utiliza, de bom grado, em um sentido, aliás, "impróprio"). Isso exclui, de início, o discurso monologal com destinatário ausente, seja oral ou escrito, monologal ou dialogal; e também o diálogo com resposta demorada, como as correspondências (mesmo as eletrônicas) ${ }^{8}$ (KERBRAT-ORECCHIONI, 2005, p. 17; grifos da autora).
\end{abstract}

A escolha da autora em limitar o conceito de interação às situações de comunicação face a face justifica o aprofundamento que ela dispensa à explicação das

\footnotetext{
8 "En effet, la notion d'interaction implique que le destinataire soit en mesure d'influencer et d'infléchir le comportement du locuteur de manière imprévisible alors même qu'il est engage dans la construction de son discours; en d'autres termes, pour qu'il y ait interaction il faut que l'on observe certains phénomènes de retroaction immediate (ou de 'réfléxivité pour reprendre un terme que la littérature interactionniste utilise volontiers dans ce sens d'ailleurs 'impropre'. Ce qui exclut d'abord le discours monologal avec destinataire absent, qu'il soit oral ou écrit, monologique ou dialogique; mais aussi le dialogue avec réponse en différe, comme les correspondances (même électroniques)" (KERBRAT-ORECCHIONI, 2005, p. 17).
} 
múltiplas configurações que apresentam as conversações: "são as interações face a face que nos interessam prioritariamente" (1990, p. 28)9. Para a autora, as conversações, além de apresentarem maior grau de interatividade ou de engajamento, são as formas mais "básicas" que podem ter as atividades linguageiras.

Segundo Kerbrat-Orecchioni (1990), as trocas proporcionadas por meio de gêneros discursivos orais que se realizam face a face apresentam diversos funcionamentos. Ao tipificar as interações, a pesquisadora opta por organizá-las a partir de alguns gêneros discursivos, como a conversação, a discussão, o debate e a entrevista. Além disso, a autora estabelece alguns critérios, como o tipo de lugar em que se dá a interação, o número e a natureza dos participantes, o propósito da interação, o grau de formalidade, o estilo e o tom (sério, lúdico, consensual, conflituoso etc.), a duração e o conteúdo. Embora utilize esses aspectos para explorar apenas modos de interação advindos de trocas orais face a face, o conjunto de critérios selecionados pela autora pode lançar luz sobre outros modos de interação, como aqueles em que há interferência de mídias, como a televisiva, a radiofônica e, mais recentemente, a mídia internet. Esses critérios, naturalmente, são fluidos, às vezes dependentes, às vezes independentes entre si, e, conforme esclarece Kerbrat-Orecchioni (1990), não suficientes, mas ajudam a explicar a configuração de certas práticas comunicativas.

Segundo Kerbrat-Orecchioni (1990), há um conjunto de gestos significativos que sinalizam o engajamento dos participantes na interação oral face a face, como os cumprimentos, as apresentações, a orientação do corpo e do olhar em direção ao interlocutor, de modo a assegurar a escuta por parte deste. Esses aspectos compõem a rede de influências mútuas de natureza diversa a que a autora se refere. Nessa rede, o engajamento entre os participantes revela o grau do que a pesquisadora chama de interatividade da troca. Portanto, quanto maior a possibilidade de fornecer resposta imediata ao locutor, maior o grau de interatividade da interação. De acordo com a pesquisadora, as interações são constituídas e interpretadas com base em "um conjunto de regras que se aplicam, em um dado quadro contextual, sobre um material de natureza

\footnotetext{
9 "ce sont ces interactions 'en face à face' qui nous intéressent prioritairement" (KERBRAT-ORECCHIONI, 1990, p. 28).
} 
semioticamente heterogêneo (unidades verbais, paraverbais e não verbais)" (1990, p. $75)^{10}$.

A autora busca, ainda, caracterizar esses sistemas comunicativos, ou material semiótico, em três grandes categorias: verbal, paraverbal e não verbal. Segundo ela, as interações ditas verbais seriam "interações em que a troca se realiza essencialmente, pelo menos na aparência, pelo viés dos significados verbais" (1990, p. 137; grifos da autora) ${ }^{11}$ e se constituiriam de materiais fonológicos, lexicais e morfossintáticos. Embora não defina as outras duas categorias, a autora traz exemplos de material semiótico de natureza paraverbal, como entonações, pausas, intensidade articulatória, particularidades da pronúncia, e características da voz; e de natureza não verbal, como as características físicas dos participantes. Kerbrat-Orecchioni (1990) apresenta, na realidade, uma aprofundada explicação desses aspectos e termina por dizer que todas essas configurações aparecem, nas interações orais face a face, cruzadas, integradas, em uma relação, na maioria das vezes, mista.

Essa breve explanação tem por objetivo salientar que a noção de interação apresentada em Kerbrat-Orecchioni (1990) fundamenta-se nas práticas comunicativas estabelecidas especificamente por meio de trocas de turno presenciais, ou seja, face a face. A análise empreendida pela autora buscou evidenciar a organização linear do texto conversacional e revelar determinadas especificidades do funcionamento dessas práticas comunicativas.

Para nós, as reflexões da autora possibilitam o surgimento de dois questionamentos importantes: 1) como podemos pensar a noção de interação a fim de que possa contemplar outras situações, cada vez mais diversificadas, que se verificam em torno dos gêneros e dos hipergêneros em meio digital?; 2) que aspectos, além dos já mencionados pela autora, podem contribuir na configuração de diferentes modos de interação? Deixemos isso em suspenso, para que conheçamos, a seguir, a proposta de Marcuschi (2010).

\footnotetext{
10 "d'un ensemble de règles qui s'appliquent, dans un cadre contextuel donné, sur un matériau de nature sémiotiquement hétérogène (unités verbales, paraverbales, et non verbales)" (KERBRAT-ORECCHIONI, 1990, p. 75).

11 "des interactions où l'échange se réalise essentiellement em apparence du moins, par le biais des signifiants verbaux" (KERBRAT-ORECCHIONI, 1990, p. 137).
} 


\section{A noção de interação sob a perspectiva de Marcuschi}

Em Marcuschi (2010 [2001 $]^{12}$ ), o objetivo principal, na parte analítica da obra (que corresponde à sua segunda metade), é descrever e discutir como se dão alguns processos de retextualização de textos orais para textos escritos. Para se chegar a essa análise, é preciso estabelecer, de antemão, posicionamentos teóricos sobre oralidade, letramento, fala e escrita. A produtiva discussão que o autor constrói sobre esses tópicos é o foco da primeira metade da obra, sobre a qual nos detemos nesta exposição.

Marcuschi (2010) tem como objetivo propor uma visão sobre as relações entre fala e escrita a qual conceba certo status de igualdade ${ }^{13}$ entre essas modalidades de uso da língua. A seguir, apresentamos as linhas gerais de sua proposta; antes, porém, adiantamos que a discussão tem como ponto de chegada a proposição de um contínuo que mostra como diversos gêneros se localizam em relação aos modos falado e escrito. A questão dos gêneros textuais, portanto, é elemento fundamental na caracterização do autor.

Salientamos, porém, que, para nós, outra dimensão fundamental, não explicitada (ou, melhor dizendo, não suficientemente explicitada) no discorrer do trabalho de Marcuschi (2010), é a interação. Essa não explicitação se deve, talvez, ao fato de que, como já se disse, em linguística textual, ainda hoje, o conceito de interação é considerado como já devidamente assentado entre a comunidade de pesquisadores da área; isso

\footnotetext{
${ }^{12}$ Achamos importante frisar a data da edição original para que a proposta de Marcuschi seja devidamente localizada no tempo. Em 2000, a internet ainda se encontrava em seus estágios iniciais, apresentando uma configuração diferente do que se veria em 2010 e ainda mais diferente do que se vê hoje. Isso explica por que os gêneros do ambiente digital não mereceram tanta atenção do pesquisador. Doravante, quando mencionarmos este trabalho, utilizaremos apenas o ano da edição que consultamos.

${ }^{13}$ Boa parte da argumentação de Marcuschi (2010) diz respeito a defender que, ao contrário do que pensa o senso comum e do que afirmam alguns nichos de investigação, não há a supremacia de uma modalidade (notadamente, a escrita) sobre outra. Ambas as modalidades são dotadas de extrema complexidade e de semelhanças as quais podem permitir um entendimento de uma "continuidade" entre elas. Embora esse seja um ponto central na reflexão do autor nessa obra, não o discutiremos aqui, uma vez que nosso foco é outro - como relacionar o trabalho de Marcuschi à proposta de que o fenômeno da interação merece maior espaço nas reflexões em linguística textual.
} de Linguística Textual, p. 141 - 164, 2020 ISSN Digital 2175-294X 
implica que não há problematização sobre o conceito nem reflexão específica sobre o fenômeno. Nossa posição, como já anunciamos, é que essa "concordância" razoavelmente universal impede que haja discussões que revelem a complexidade do fenômeno, que deve ser descrita a fim de que outras discussões - sobre gênero, sobre texto, sobre coerência - sejam enriquecidas.

A interação está intrinsecamente ligada à reflexão de Marcuschi, haja vista o autor sustentar que "são os usos que fundam a língua e não o contrário" (MARCUSCHI, 2010, p. 9; grifo do autor). Isso leva o autor a afirmar que:

não se pode tratar as relações entre oralidade e letramento ou entre fala e escrita de maneira estanque e dicotômica. A proposta é que se vejam essas relações dentro de um quadro mais amplo no contexto das práticas comunicativas e dos gêneros textuais (2010, p. 9; grifo nosso).

Falar em usos e práticas comunicativas como alicerces para uma concepção de linguagem e um trabalho analítico de relações entre modalidades de linguagem implica considerar que a interação é parte essencial neste fazer teórico, o que possibilita evitar “posturas estanques e estáticas” (MARCUSCHI, 2010, p. 10).

Aliás, é a interação que embasa a decisão do autor de destacar, como instâncias mais significativas para se entender a complexidade dos tipos de comunicação (“empacotados” em gêneros textuais), não a fala e a escrita, mas a oralidade e o letramento ${ }^{14}$, estes entendidos como "atividades interativas e complementares, no contexto das práticas sociais e culturais" (MARCUSCHI, 2010, p. 16; grifo nosso), as quais são distribuídas de diversas maneiras na comunicação cotidiana. Em paralelo a essas práticas - que concernem à ação dos sujeitos -, estão as modalidades de produção textual-discursiva - fala e escrita, estando, obviamente, a fala mais ligada à oralidade e a escrita mais ligada ao letramento.

A fim de entendermos a diferença entre letramento/oralidade, de um lado, e escrita/fala, do outro, vejamos dois exemplos:

\footnotetext{
${ }^{14} \mathrm{Ou}$ letramentos, no plural, como Marcuschi às vezes usa, acatando recomendação de Street (apud MARCUSCHI, 2010).
} 
- A situação de interação na qual se inclui um artigo acadêmico pressupõe um conjunto de condições, digamos, gerais, as quais vão além das condições mais especificamente atreladas ao gênero; algumas dessas condições seriam o distanciamento físico entre os participantes, a ausência de intimidade entre eles, a possibilidade de atingir um número ilimitado de pessoas, a possibilidade de que tal texto permaneça disponível “eternamente”. Isso tudo caracterizaria uma prática de escrituralidade ${ }^{15}$, a qual é materializada, predominantemente, por meio da modalidade escrita;

- A situação de interação na qual se inclui uma conversação espontânea pressupõe um conjunto de condições também gerais: a proximidade física e a intimidade entre os participantes, a possibilidade de interferência simultânea nas falas uns dos outros, a impossibilidade de retenção da materialidade textual. Essas condições permitem a emergência de uma prática de oralidade, a qual se concretiza, primordialmente, por meio da modalidade falada.

O interessante, na discussão continuada por Marcuschi, é que, devido à enorme complexidade do ato de comunicar - a qual decorre da condição de que são muitos os propósitos comunicativos e muitas mais as situações em que tais propósitos se efetivam -, há mesclas entre as modalidades escrita e falada, devido ao fato de que as práticas de escrituralidade e oralidade não são dispostas de forma polarizada, mas sim na forma de um continuum. Há, por exemplo, situações de comunicação mediadas pela modalidade escrita as quais se aproximam bastante de um contexto mais característico de oralidade; o bilhete, por exemplo, pode ser incluído nessa caracterização. Do mesmo modo, há

\footnotetext{
15 Neste caso, estamos empregando termo usado por Hilgert (2019) em substituição ao termo "letramento" usado por Marcuschi. Hilgert argumenta, com propriedade, que o que Marcuschi (2010) chama de "letramento" - conjunto de práticas que, por conta de características específicas, é concretizado de forma mais eficaz por meio da modalidade escrita - pode ser mais bem denominado pelo termo "escrituralidade". Isso evita, inclusive, a identificação, não muito apropriada, entre o que Marcuschi apregoa e o que se conhece como "estudos de letramento" (como os presentes, por exemplo, em Soares (1998) e Kleiman (1995)). A partir deste ponto, optamos por usar "escrituralidade" no lugar de "letramento".
} 
situações, como a apresentação de uma palestra, em que a modalidade oral é utilizada numa prática que guarda características importantes da escrituralidade.

De modo simplificado, pode-se considerar que há:

- situações mais características de escrituralidade, em que o modus operandi atende a um conjunto de critérios que podem ser ligados a uma "prática de escrita prototípica”;

- situações mais características de oralidade, em que o modus operandi atende a um conjunto de critérios que podem ser ligados a uma "prática de fala prototípica";

- situações intermediárias, que abrangem características tanto da escrituralidade quanto da oralidade, mas de modo menos prototípico (em relação a uma ou mais dessas características).

Marcuschi (2010) põe, como elemento determinante nessa mescla, a relação entre a concepção discursiva de um gênero - se mais característico da escrituralidade, se mais característico da oralidade ${ }^{16}$ - e o meio de produção - se sonoro (ligado à fala) ou gráfico (ligado à escrita). O entrecruzamento entre essas dimensões propiciaria, em princípio ${ }^{17}$, quatro possibilidades de configuração para os gêneros textuais:

\footnotetext{
${ }^{16}$ Nessa parte de sua exposição, o autor não usa os termos "escrituralidade" e "oralidade", mas sim "oral" e "escrito". O que se percebe é que não há, por parte do autor, o controle terminológico que ele apresenta em partes anteriores da obra, na qual houve o cuidado de caracterizar os pares "oralidade e letramento" e "fala e escrita" como relacionados a esferas distintas da linguagem. Para mantermos coerência com essa caracterização, optamos, nesta exposição, por manter os termos que, julgamos, manteriam o respeito ao paralelo definido por Marcuschi.

${ }^{17}$ Dizemos que as quatro possibilidades apresentadas são apenas uma proposta esquematizadora inicial porque, dentro de uma visão não compartimentalizada, as configurações dos gêneros podem se dar por mesclas dentro dessas possibilidades. Por exemplo, no eixo da concepção discursiva, entre uma ponta extrema e a outra - polos em que se encontram gêneros mais característicos de escrituralidade e gêneros mais característicos de oralidade -, há muitas possibilidades: há os que não estão no polo da escrituralidade, mas estão próximos dele; há os que não estão no polo da oralidade, mas estão próximos dela; há os que estão na metade entre um polo e outro; há os que não estão no ponto de metade entre os polos, mas se encontram próximos a ele, de um lado ou de outro.
} 
- gêneros de concepção oral e realização sonora, como a conversa espontânea face a face;

- gêneros de concepção oral e realização gráfica, como o bilhete;

- gêneros de concepção "escritural" e realização sonora, como a apresentação de telejornal;

- gêneros de concepção "escritural" e realização gráfica, como o editorial de jornal.

Para representar graficamente essa condição, Marcuschi propõe o gráfico ${ }^{18,19} \mathrm{a}$ seguir (utilizado em inúmeros trabalhos sobre o tema):

Gráfico 1 - Representação do contínuo dos gêneros textuais na oralidade e na escrituralidade

\footnotetext{
${ }^{18}$ Na proposta de Marcuschi (2010), os gêneros são ou apenas falados ou apenas escritos.

${ }^{19}$ No gráfico original de Marcuschi, os termos que se encontram nos polos do contínuo, em caixa alta, são "FALA" e "ESCRITA". Pensamos, contudo, que o que caracteriza o contínuo não é a modalidade de linguagem, mas sim as características que definem as diferentes práticas discursivas, por isso optamos pelo uso dos termos "ORALIDADE" e "ESCRITURALIDADE". 


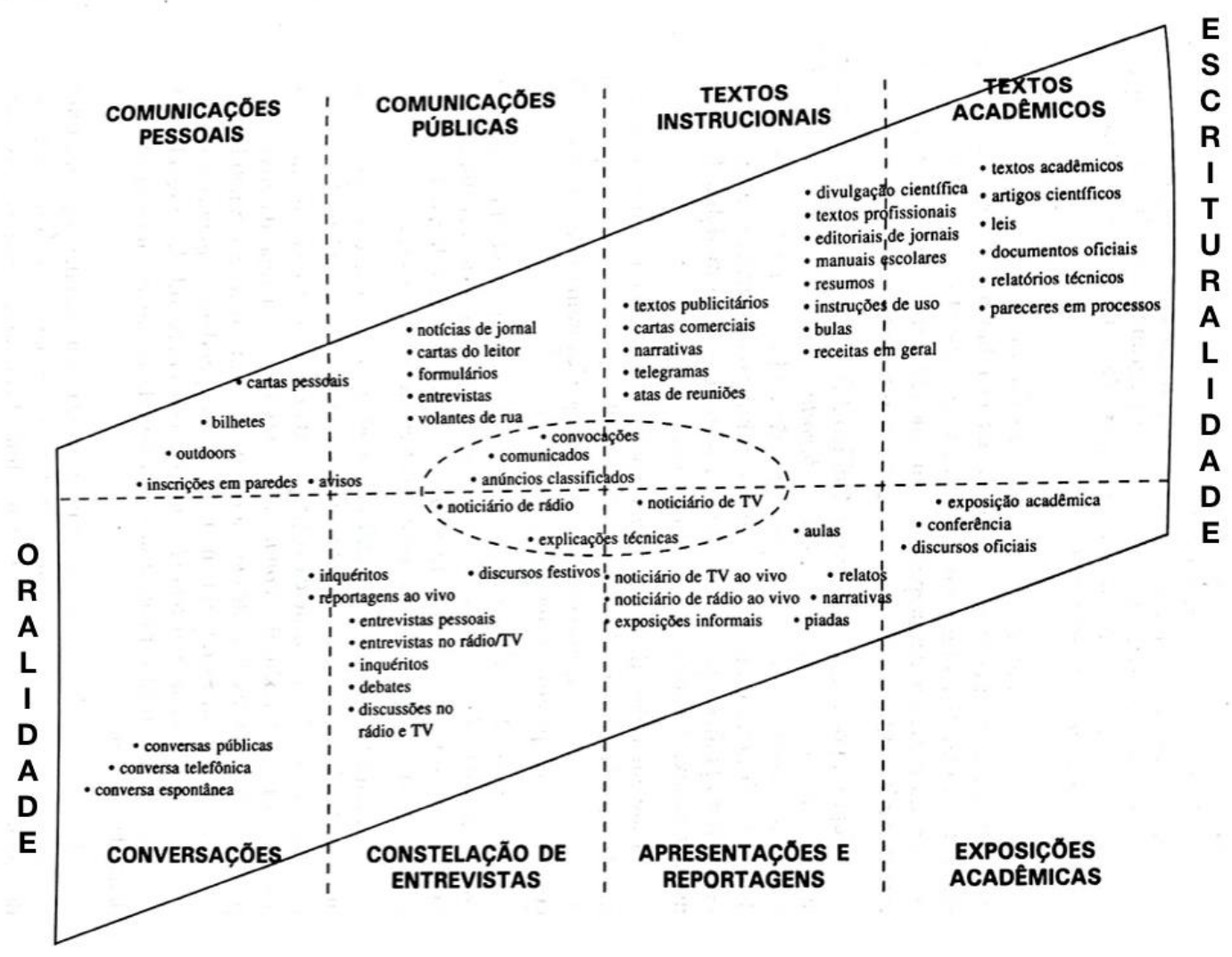

Fonte: Marcuschi (2010), adaptado pelos autores.

Nesse gráfico, a linha pontilhada horizontal estabelece a distinção entre os meios de realização: acima da linha, os gêneros de realização gráfica; abaixo, os de realização sonora. Nos dois polos do contínuo, aparecem os nomes “ORALIDADE” e “ESCRITURALIDADE”; representando o eixo da concepção discursiva.

O gráfico é, a nosso ver, eficaz para mostrar a diversificação dos gêneros. Para nós, é nítido que tal diversificação está ligada ao fenômeno da interação. O que Marcuschi demonstra, ainda que não o diga explicitamente, é que são os tipos de interação diferentes que geram a multiplicidade de gêneros. Isso, por si, é suficiente para que aleguemos que a interação - como fenômeno constitutivo das práticas de linguagem - precisa ser mais estudada, a fim de que se tenha um entendimento mais adequado do que está em pauta quando se analisa a produção e a compreensão de sentidos nos textos. Essa é uma tarefa da qual a linguística textual dos dias de hoje não pode se furtar.

Assentados que estamos de que há vários modos de interação - e de que levar em conta essa variedade é uma tarefa investigativa importante -, cabe, agora, refletir sobre 
o que configura os diferentes modos, ou seja, cabe propor definir que elementos são responsáveis por definir as características dos modos de interação uns em relação aos outros.

\section{Os modos de interação: uma problematização}

Conforme salientamos, Kerbrat-Orecchioni (1990, 1992, 2005) estabelece um vínculo muito estreito entre o conceito de interação e as situações de conversação face a face. Admitimos, com a autora, que a interação diz respeito a toda troca comunicativa, porém, em sua configuração, é preciso considerar fatores que revelam modos de interagir para além daqueles que se dão face a face. A interação é, portanto, do âmbito da condição humana e concerne, como a autora e outros pesquisadores revelam, a todo processo comunicativo pelo qual os interlocutores, conduzidos por seus propósitos, visam influenciarem-se mutuamente. Acrescentamos, além disso, que esse processo pode ter diversas configurações e gerar modos de interação distintos.

Marcuschi (2010), por sua vez, apresenta um quadro teórico em que as distintas possibilidades de interação definem a multiplicidade de gêneros. Nossa compreensão da proposta do autor permite reconhecer que os elementos geradores dessa diversidade seriam a concepção discursiva e o meio de realização. Cremos, contudo, que isso não é suficiente para um entendimento mais esclarecedor sobre os diferentes modos de interação.

Entendemos que não há2o, para a concepção discursiva e o meio de realização, uma caracterização exaustiva a qual defina que fatores são elencados para definir essas instâncias. O que é, exatamente, uma concepção discursiva? Que esse elemento é fundamental na caracterização dos tipos de interação, não nos resta dúvida. Mas falta

\footnotetext{
20 Ao afirmarmos isso, não estamos dizendo, nem implicitando, que essa falta decorre de qualquer problema na teorização de Marcuschi. O que estamos apontando como falta é algo que não era preocupação do autor, mas é importante para nós. Apenas isso.
} 
refletirmos sobre que aspectos são constitutivos das concepções. O mesmo parece ser necessário para precisar o que vem a ser o meio de realização.

No caso particular da concepção discursiva, parece haver a interferência do grau de formalidade - de modo que a esfera da escrituralidade se revestiria do traço +formal, e a da oralidade, do traço -formal. Mas isso também é insuficiente na medida em que não se diz, também para o grau de formalidade, quais são os fatores que o definem. A nosso ver, fatores importantes, não apenas para caracterizar o grau de formalidade, mas os processos de interação como um todo, estão intimamente ligados aos sujeitos da interação: o papel social, o modo de gestão (monologal X dialogal) e as possibilidades e limites do projeto de dizer parecem-nos fundamentais - até mais do que as relações entre fala e escrita - para compreender os variados tipos de interação.

Também consideramos como fundamental o meio físico de realização dos textos. A onipresença da internet traz a reboque a possibilidade de o meio físico assumir novas configurações, o que, dentre outras mudanças, modifica a forma como se entende separação entre o sonoro e o gráfico e deixa mais complexas as manifestações do meio gráfico - que passa a ser concretizado no meio impresso e no meio digital. Isso tudo permite a emergência de novas possibilidades de sincronicidade e assincronicidade (que parecem estar ligadas, antes do advento da internet, respectivamente, à oralidade e à escrituralidade).

Temos, portanto, um conjunto de aspectos que devem ser manejados para se compreender, de forma mais ampla, o fenômeno da interação. Esses aspectos, não esgotáveis e inerentemente ligados aos gêneros discursivos, seriam os sistemas semióticos envolvidos, os papéis sociais exercidos pelos interlocutores, além do nível de sincronicidade, do tipo de gestão de vozes e do tipo de mídia relacionados à interação. A seguir, fazemos uma breve discussão sobre esses aspectos.

\section{Os sistemas semióticos}


O que estamos considerando sistema semiótico coincide com o que KerbratOrecchioni (1990) optou por chamar de "material semiótico", ou seja, seriam os sistemas comunicativos disponíveis na linguagem humana, como as semioses oral, escrita, imagética, gestual e sonora. Vale ressaltar, porém, algumas particularidades que assumiremos nesta discussão. O sistema semiótico oral é aquele sistema relacionado à presença do canal fônico (canal natural humano vinculado, portanto, ao aparelho fonador) e cuja manifestação pode se dar tanto em situações de interação em presença quanto em ausência. Nas conversações cotidianas e nas aulas tradicionais, por exemplo, o sistema semiótico oral se manifesta em presença físico-espacial dos interlocutores. Por outro lado, reuniões via Skype e mensagens de áudio via Whatsapp são exemplos em que o sistema semiótico oral se realiza na ausência físico-espacial dos interlocutores. Em todas essas situações, portanto, admitimos que há modos de interação cuja configuração apresenta o sistema semiótico oral.

Outra particularidade relaciona-se ao sistema semiótico imagético. Com o advento de gêneros e hipergêneros ${ }^{21}$ que se apresentam em contexto digital, é cada vez mais comum nos depararmos com modos de interagir cuja configuração envolve tanto imagens estáticas, como as que verificamos nas tirinhas, quanto imagens dinâmicas, como se visualiza nos GIFs animados. Diferentemente de Kerbrat-Orecchioni (1990, 1992, 2005), que objetivou dar um foco maior às interações em cuja configuração apareciam os sistemas semióticos orais e gestuais (como é o caso das conversações e de outras situações face a face a que a autora se refere), nesta proposta sugerimos lançar um olhar mais amplo, pois, para contemplar certos modos de interação digital, o cruzamento de todas essas semioses (incluindo, obviamente, a escrita e a sonora) é inevitável.

\footnotetext{
${ }^{21}$ Temos tomado a noção de Bonini (2011) de que os hipergêneros corresponderiam a um "agrupamento de gêneros para compor uma unidade maior" (p. 681) ou a "um gênero formado por outros gêneros" (p. 682). Embora discordemos de alguns posicionamentos do autor sobre o conceito de hipergênero, admitimos a ideia de que os hipergêneros parecem funcionar como um compósito de gêneros que se relacionam entre si. Em trabalhos futuros, pretendemos discutir mais detalhadamente a problemática em torno desse termo.
} 


\section{Os papéis sociais}

Além disso, os papéis sociais exercidos pelos participantes da interação atuam como aspecto configurador de modos de interação distintos. De fato, se ministra uma palestra em um evento de linguística ou se estabelece uma conversa cotidiana em uma mesa de bar com os amigos, o locutor cumpre papéis sociais diferentes que o compelem, por questões sociais, a revelar modos de interação distintos.

\section{O grau de sincronicidade}

Da mesma forma, o grau de sincronicidade é também aspecto relevante na configuração de modos de interação. Na conversa telefônica, por exemplo, é comum que o grau de sincronicidade seja alto, pois se espera que, nessa situação de interação, a resposta do interlocutor (mesmo que seja um retorno em forma de silêncio ou de certos sons com função fática) se dê logo após o momento em que o locutor diz alguma coisa. Por outro lado, nas interações que acontecem por meio dos e-mails pessoais, o nível de sincronicidade é flutuante, pois dependerá de fatores, como a conexão à internet, a frequência de acesso à caixa de mensagens pelo interlocutor ou o interesse do interlocutor em fornecer ou não resposta ao locutor.

\section{A gestão de vozes}

Outro aspecto importante na configuração de modos de interação é o que temos chamado de gestão de vozes. Esse fator tem origem em Amossy (2017) e diz respeito ao 
nível de gestão do interlocutor sobre o que está sendo dito no texto - mais monogerido ou mais poligerido. Embora lide com a problemática da modalidade argumentativa polêmica, temática fora do escopo deste artigo, a autora diferencia gêneros de "discurso polêmico" de gêneros de “interação polêmica”. Em um diálogo com Kerbrat-Orecchioni, a autora considera que, no discurso polêmico, somente um dos interlocutores está presente na situação comunicativa (KERBRAT-ORECCHIONI, 1980, p. 9). Por outro lado, na interação polêmica, dois ou mais interlocutores se engajam na interação e o discurso se dá de maneira dialogal, por meio, portanto, da troca de turnos (AMOSSY, 2017, p. 72). As autoras se referem, nesses casos, a uma questão de administração ou de gerência do dizer. Acreditamos que essa gestão de vozes se dá em níveis e está relacionada a certos gêneros que se dão em modos de interação mais monogeridos ou mais poligeridos.

Em uma situação de interação mais monogerida, o locutor administra o que será apresentado no texto. Em uma notícia de jornal impresso, por exemplo, a interação se revela mais monogerida, pois o locutor responsável pelo que está sendo apresentado no texto elege o que será dito, o que será recortado, que tipo de discurso (direto ou indireto, por exemplo) será priorizado, entre outras escolhas. Por outro lado, nas situações de interação mais poligeridas, como o próprio nome sugere, os participantes assumem o papel simultâneo de locutor e interlocutor, tendo oportunidade de construir o que está sendo apresentado no texto, de maneira, por assim dizer, mais democrática, tendo em vista estar em jogo a possibilidade do diálogo.

Ainda tomando a gestão de vozes como aspecto, e a fim de se perceber a importância de se considerar os distintos modos de interação como elementos importantes para a configuração dos sentidos, propomos uma exemplificação com o gênero notícia. Julgamos que a configuração discursiva desse gênero se modifica, em ampla medida, a depender do modo de interação de que um dado texto noticioso participe. Numa situação mediada pelo impresso, a notícia revelará as características apresentadas no parágrafo anterior: trata-se de textos monogeridos, e isso determina o modo como os interlocutores “respondem” a esses textos. Quando a notícia é publicada em uma interação estabelecida no meio digital, passando a ser uma webnotícia, algumas 
condições, que só acontecem nesse meio, possibilitam que os textos passem por uma gestão mais poligerida.

Consideremos, para análise, o exemplo a seguir.

Exemplo 1 - Cópia da tela de webnotícia publicada na página do O Povo Online no Facebook com destaque para recursos que proporcionam uma interação mais poligerida

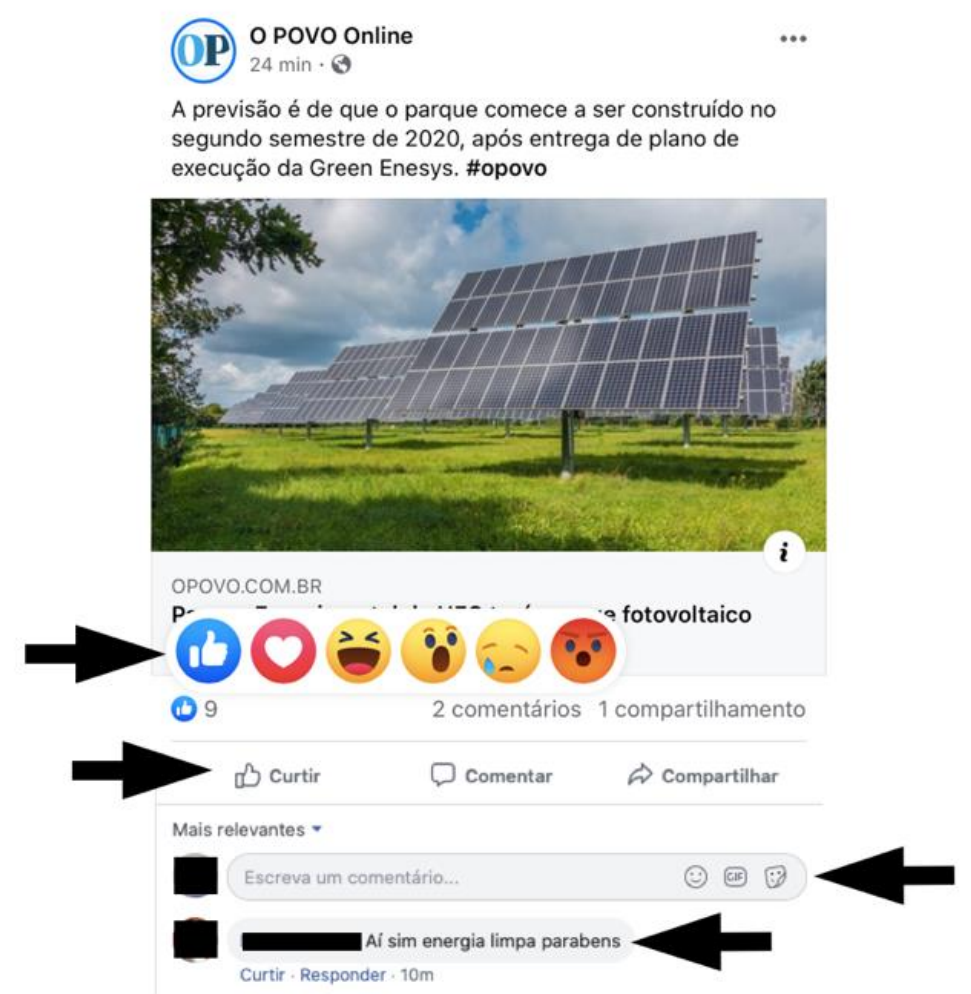

Fonte: Página O Povo Online disponível no Facebook, em 22 de jan. de 2020.

Nesse exemplo, as setas destacam os recursos de "curtir" (setas à esquerda) e "comentar" (setas à direita) que permitem aos interlocutores uma interação mais poligerida, pois, nesse caso, os participantes são convidados a construir conjuntamente aquilo que está sendo dito/construído no hipergênero webnotícia. Por meio dos comentários, que podem ser manifestados tanto pelo uso da semiose escrita quanto pela 
utilização do sistema semiótico imagético - estático (no caso da inserção de emojis, por exemplo) ou dinâmico (no caso da inserção de GIF animado e de outras imagens em movimento) -, os interlocutores participam do gerenciamento do dizer que está em tela e, assim, por meio de um modo de interagir diferente daqueles casos mais monogeridos, cooperam na construção do que está sendo dito. Temos, então, que, a depender do modo de interação, a construção da coerência se estabelece a partir de diferentes processos de participação dos sujeitos.

\section{Os tipos de mídia}

Ainda sobre os aspectos apresentados, destacamos a mídia internet, que exerce um papel de destaque, especialmente com a ampliação das possibilidades de interação por intermédio de Whatsapp, Facebook, Twitter e Instagram, para citar alguns exemplos. A noção de mídia que adotamos advém das reflexões empreendidas em Bonini (2011) ${ }^{22}$. O autor define o termo como "tecnologia de mediação linguageira" (p. 688). A mídia seria, para o pesquisador, um elemento "contextualizador no interior do qual o gênero circula" (p. 688).

Nessa perspectiva, consideramos a internet como uma mídia mais ampla que abarca, por assim dizer, outras mídias as quais, de fato, funcionam, mais diretamente, como tecnologia mediadora das interações digitais on-line. Um exemplo disso pode ser a mídia Whatsapp, que se localiza na mídia internet, mas que, como tecnologia, apresenta características específicas que outras mídias da internet não apresentam. É o que podemos reconhecer no exemplo a seguir:

\footnotetext{
${ }^{22}$ Para a finalidade deste artigo, acreditamos que a definição de mídia apresentada é suficiente. Por outro lado, admitimos que, assim como a noção de hipertexto, a discussão em torno do termo "mídia" é complexa, o que exige, portanto, reflexões para trabalhos futuros.
} 
Exemplo 2 - Conversa de Whatsapp em que se visualizam recursos disponíveis para a interação dos interlocutores

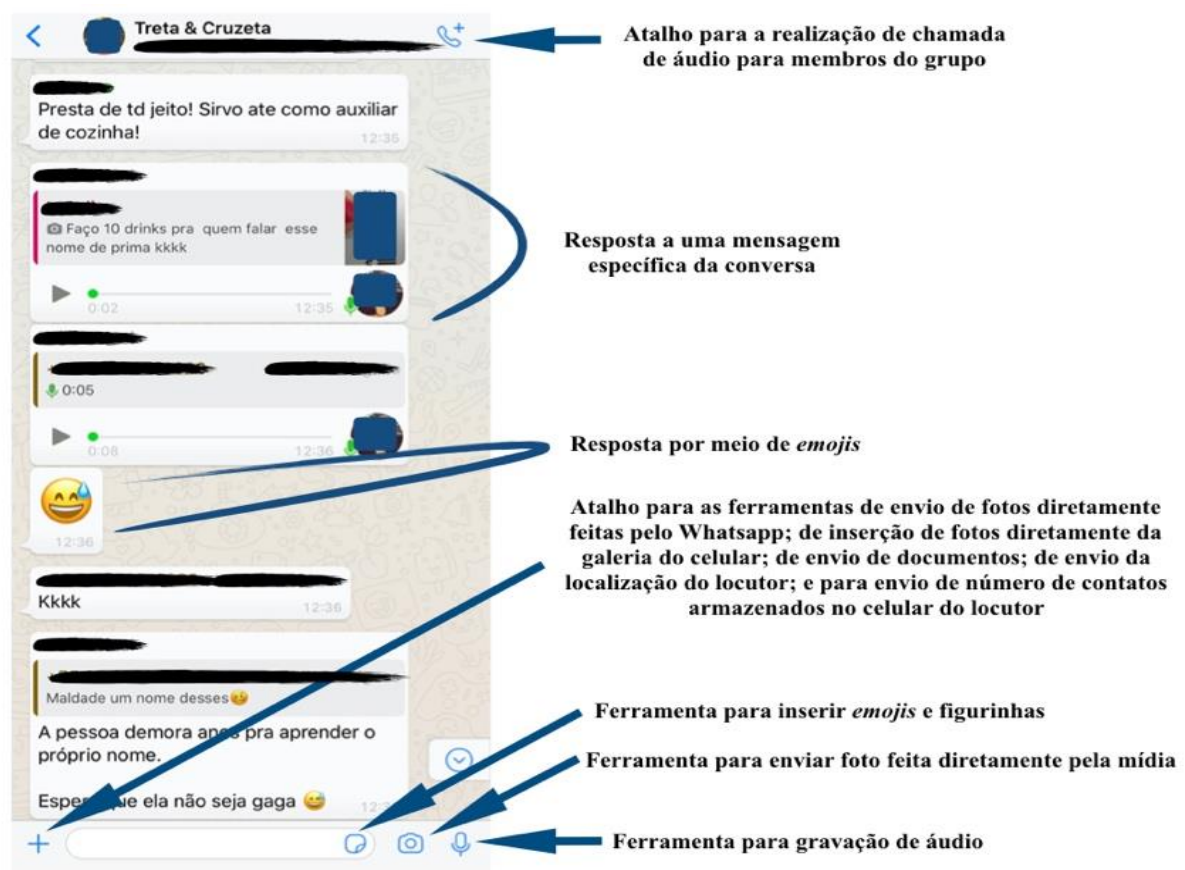

Fonte: cópia da tela de conversa realizada no grupo de Whatsapp “Treta \& Cruzeta”, em 23 de jan. de 2020 (arquivo pessoal).

Nesse exemplo, visualizamos uma parte dos recursos disponíveis por meio da mídia Whatsapp, como a possibilidade de realização de chamadas de áudio, de envio de gravação de áudio e de encaminhamento de fotos, emojis, figurinhas e documentos. Esse conjunto de recursos ilustra a diversidade de modos de interação que as mídias digitais propiciam aos interlocutores. Outras mídias, como Facebook, Instagram e Twitter, para citar as mais utilizadas no Brasil, também apresentam uma série de ferramentas que têm modificado o modo como interagimos a partir dos gêneros e hipergêneros.

\section{Conclusão}


Kerbrat-Orecchioni (1990, 1992, 2005) explorou aspectos da interação que, embora limitados às situações face a face, apontam para uma diversidade de modos de interagir. Sob outra perspectiva, Marcuschi (2010) apresentou um contínuo de gêneros discursivos os quais dispõem de características mais ou menos próximas dos polos da oralidade e da escrituralidade. Embora não tenha se preocupado em conceituar o termo “interação", o autor evidenciou uma diversidade de práticas comunicativas que, na realidade, são intrinsecamente dependentes da configuração das interações. Neste artigo, buscamos esclarecer que as inovações trazidas por esses autores já nos direcionavam para a multiplicidade de modos de interagir, o que, por sua vez, encaminhou-nos a evidenciar novos aspectos da interação, como aqueles em que as mídias digitais e seus recursos entram em jogo.

Vemos, então, que é possível propor uma caracterização mais complexa do fenômeno da interação, que se baseie por critérios os quais revelam a natureza textual e discursiva de diferentes gêneros. Julgamos que uma discussão mais profícua sobre esses critérios, relacionados a modos de interação diversos, pode trazer contribuições teóricas importantes para a LT, na medida em que essa prática investigativa permite reforçar a natureza sociodiscursiva e interacionista da área. Isso poderá permitir que, ao se considerar o uso das estratégias de construção da coerência, os analistas tenham como foco, também, a consideração de que modos de interagir são determinantes para a configuração dos sentidos.

\section{Referências}

AMOSSY, Ruth. Apologia da polêmica. São Paulo: Contexto, 2017.

BEAUGRANDE, Robert de. New foudations for a science of text and discourse: cognition, communication and the freedom of access to knowledge and society. Norwood: Ablex, 1997.

BONINI, Adair. Mídia / suporte e hipergênero: os gêneros textuais e suas relações. $R B L A$, 
Belo Horizonte, v. 11, n. 3, p. 679-704, 2011. Disponível em <http://www.scielo.br/pdf/rbla/v11n3/o5.pdf>. Acesso em nov. 2018.

HILGERT, José Gaston. Gênero oral: rediscutindo critérios para sua definição. [Comunicação apresentada por ocasião do evento ABRALIN5o - Linguística na Contemporaneidade: Desafios, Debates e Propostas. Maceió: UFAL, 2019].

KERBRAT, ORECCHIONI, Catherine. La polémique et ses definitions. In: GELAS, Nicole; KERBRAT-ORECCHIONI, Catherine (Org.) Le discours polemique. Lyon: Presses Universitaires de Lyon, 1980, p. 3-40.

_. Les interactions verbales. Tome 1. Paris: A. Colin, 1990. . Les interactions verbales. Tome 2. Paris: A. Colin, 1992. Le discourse en interaction. Paris: A. Colin, 2005.

KLEIMAN, Angela. (Org.). Os significados do letramento: uma perspectiva sobre a prática social da escrita. Campinas: Mercado das Letras, 1995.

MARCUSCHI, Luiz Antônio. Da fala para a escrita: atividades de retextualização. São Paulo: Cortez, 2010.

SOARES, Magda. Letramento: um tema em três gêneros. Autêntica Editora, 1998.

Recebido em 06/03/2020.

Aprovado em 31/05/2020. 